\title{
Viscosity and density of a two-phase drilling fluid
}

\author{
O. ALEMANY, ${ }^{1}$ H. MITYAR ${ }^{2}$ \\ ${ }^{1}$ Laboratoire de Glaciologie et Géophysique de I'Environnement du CNRS (associé à I'Université Joseph Fourier-Grenoble I), \\ 54 rue Molière, BP 96, 38402 Saint-Martin-d'Hères Cedex, France \\ E-mail: alemany@lgge.obs.ujf-grenoble.fr \\ ${ }^{2}$ SIMAP-pamir team, UMR 5266, Domaine Universitaire, BP 75, 38402 Saint-Martin-d'Hères Cedex, France.
}

\begin{abstract}
Many ice-core drilling projects expect to reach depths greater than $\mathbf{1 0 0 0} \mathbf{m}$. At such depths it is necessary to fill the borehole with a fluid to compensate the ice pressure and avoid the resulting significant hole closure. Knowledge of the ice-chips and drilling-fluid circulation parameters (e.g. flow rate, pressure drop, velocity) is essential for understanding the behaviour of the fluid around the drill and will support drill design through a better parameterization in models. A characterization of the dynamic viscosity and of the density of the ice-chips and drilling-fluid mixture is required to calculate these circulation parameters. The goal of this study is to propose a method to calculate, to a first approximation, both these physical properties. The relationships presented here have been established after experimentation, building on prior assumptions taken from the literature.
\end{abstract}

\section{INTRODUCTION}

Deep ice-core drilling operations require that the borehole be filled with a fluid to compensate the ice pressure at great depth (Talalay, 2002a, b). The drilling fluid used for recent European drilling projects such as the North Greenland Icecore Project (NorthGRIP; Dahl-Jensen and others, 2002), the European Project for Ice Coring in Antarctica (EPICA) Dome C (Augustin and Antonelli, 2002), Berkner Island, Antarctica, (Mulvaney and others, 2008) or Talos Dome, Antarctica, (Sala and others, 2008) is mainly a mixture of a petroleum oil product, similar to kerosene (with a density of $800-850 \mathrm{~kg} \mathrm{~m}^{-3}$ at $-30^{\circ} \mathrm{C}$ ), with dichlorofluoroethane HCFC-141b (with a density of $1325 \mathrm{~kg} \mathrm{~m}^{-3}$ at $-30^{\circ} \mathrm{C}$ ) added to increase the density to as close as possible to the mean ice density. Although these binary drilling fluids have already been described (Talalay and Gundestrup, 1999, 2002a, b), there is still much to learn about the properties of the mixture of drilling fluid and ice chips.

The drilling-fluid/ice-chips mixture has been considered as a homogeneous fluid with mean physical properties that correctly characterize the real solid/liquid suspension. To extend this to a hydraulic calculation for the lower part of a drill requires knowledge of the two main fluid parameters: (1) the fluid density and (2) the fluid viscosity.

The goal of this paper is to propose a method to calculate, to a first approximation, both these parameters. The drilling fluid chosen in the experiments performed in cold rooms at Laboratoire de Glaciologie et Géophysique de I'Environnement (LGGE) is a mixture of Exxsol D60 solvent and dichlorofluoroethane HCFC-141b, with a mass concentration of HCFC-141b of $31.7 \%$ (the mass concentration usually given in the literature (Talalay and Gundestrup, 2002a, b)). This drilling fluid has been used in, for example, the Berkner Island project (Mulvaney and others, 2008). The results obtained in this study could easily be used for other drilling fluids (e.g. D40 and HCFC-141, D30 and HCFC141, jet fuel A1 and densifier).

The following terms are used:

(a) Binary drilling fluid: mixture of kerosene solvent (here Exxsol D60) and densifier (here HCFC-141b) with a mass concentration of HCFC-141b of $31.7 \%$. (b) Drilling compound: a two-phase mixture of drilling fluid (D60 and HCFC-141b as defined in (a)) with ice chips in suspension. This drilling compound has been characterized for different ice-chip mass concentrations.

\section{MEAN DENSITY RELATIONSHIP FOR THE DRILLING COMPOUND}

The densities of the drilling fluids are well documented (Talalay and Gundestrup, 2002a, b). In the case of a mixture of D60 and HCFC-141b, an empirical expression (Talalay

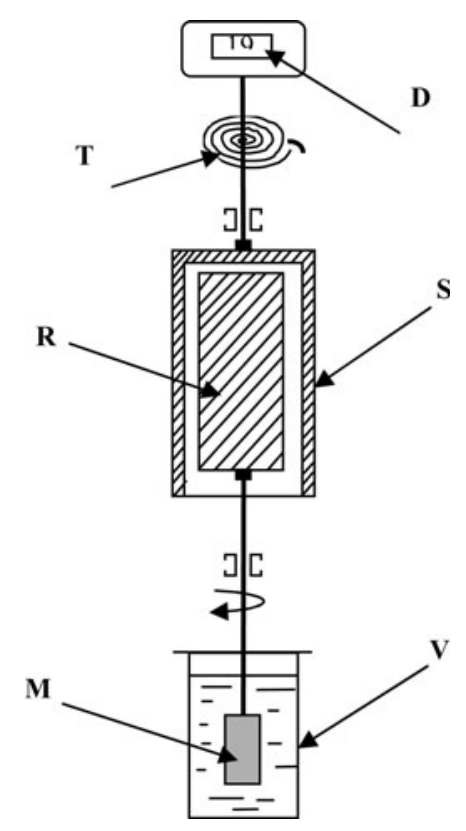

Fig. 1. Commercial viscosimeter Lamy TVe-05. A d.c. motor drives an axle in rotation. The viscosity is deduced from the torque measured to keep the axle a constant speed. $\mathrm{T}$ is the torsion spring, $\mathrm{D}$ is the display for the viscosity value, $\mathrm{R}$ is the a.c. motor rotor, $\mathrm{S}$ is the a.c. motor stator, $M$ is the moving body in the fluid and $V$ the vessel in which the fluid is placed. 


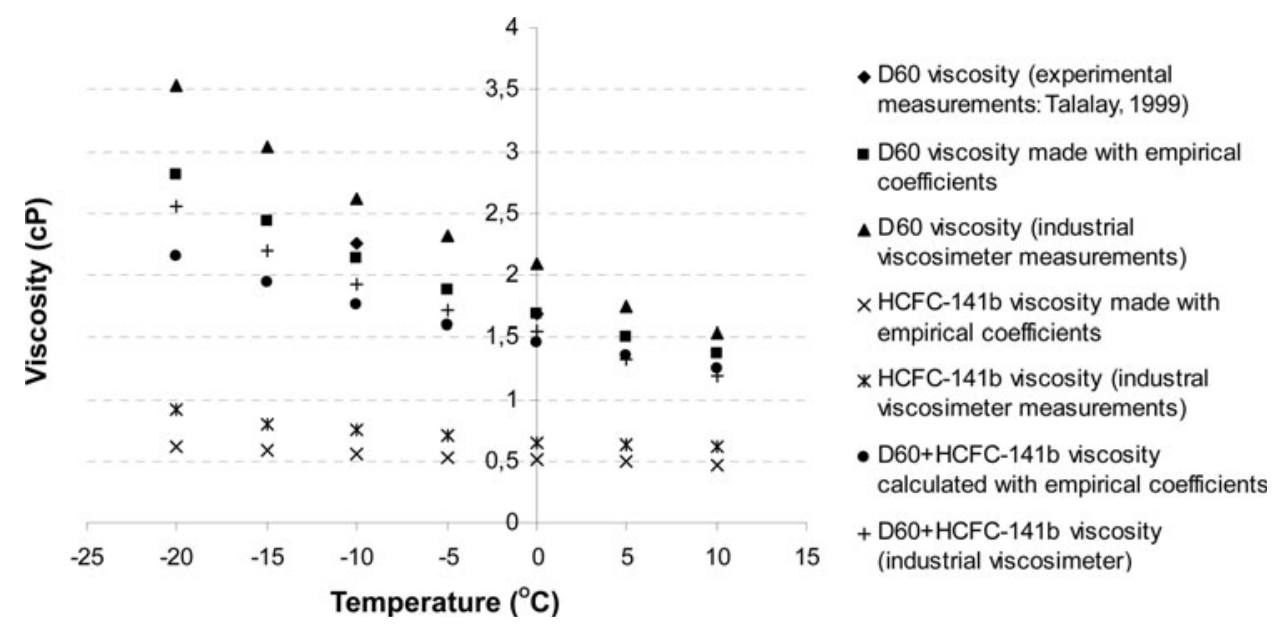

Fig. 2. Comparison of the viscosity at various temperatures for different fluids measured with an industrial (Lamy TVe-05) viscosimeter, with theoretical values (for water), and calculated according to the empirical relationship from Talalay and Gundestrup (1999).

and Gundestrup, 2002a, b) of the density in $\mathrm{kg} \mathrm{m}^{-3}$ obtained over the temperature range $t$ from 0 to $-30^{\circ} \mathrm{C}$ is given by:

$$
\rho=-0.899 t+908 \text {. }
$$

More generally, the expression for the density of a binary fluid mixture $\left(\rho_{\mathrm{fl}}\right.$ in $\left.\mathrm{kg} \mathrm{m}^{-3}\right)$ where the fluids do not react together is:

$$
\rho_{\mathrm{fl}}=\frac{\rho_{1}}{1-\left[\frac{C_{\mathrm{M}}\left(\rho_{2}-\rho_{1}\right)}{100 \rho_{2}}\right]^{\prime}},
$$

where $\rho_{1}$ is the fluid density, $\rho_{2}$ is the densifier density in $\mathrm{kg} \mathrm{m}^{-3}$ and $C_{\mathrm{M}}$ is the mass concentration of densifier in \%. It is also commonly agreed that the pure ice-chip density is $\rho_{\text {ice }}=920 \mathrm{~kg} \mathrm{~m}^{-3}$. We consider that, to a first approximation, the two-phase fluid compound (ice-chips/drilling-fluid) density $\rho_{\mathrm{m}}$ can be calculated by the expression:

$$
\rho_{\mathrm{m}}=\alpha_{\mathrm{fl}} \rho_{\mathrm{fl}}+\alpha_{\mathrm{ice}} \rho_{\text {ice, }}
$$

where $\alpha_{\mathrm{fl}}$ is the volume concentration of pure drilling fluid, $\alpha_{\text {ice }}$ is the volume concentration of pure ice and $\rho_{\mathrm{fl}}$ is the density of drilling fluid.

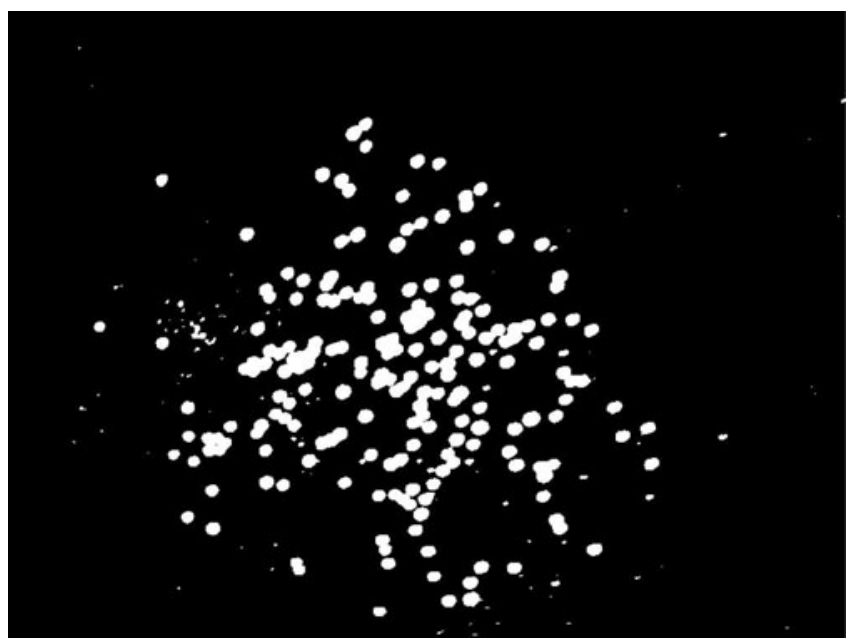

Fig. 3. Photo of small polystyrene balls with diameter $0.7 \mathrm{~mm}$.

\section{VISCOSITY INVESTIGATIONS}

\section{Viscosity of a two-component fluid compound}

It is relatively easy to find relationships that give the viscosity of compound fluids. All the relationships found in the literature have been established for Newtonian fluids, with solid spherical particles in suspension. The relationship that can be used in most conditions, established by Ishii and Mishima (1984), predicts the viscosity of a two-phase fluid for all types of spherical particles and even for high particle concentration:

$$
\mu_{\mathrm{m}}=\mu_{\mathrm{c}}\left(1-\frac{\alpha_{\mathrm{p}}}{\alpha_{\mathrm{pm}}}\right)^{-2.5 \alpha_{\mathrm{pm}}}
$$

where $\mu_{\mathrm{m}}$ is the two-phase fluid equivalent dynamic viscosity $(\mathrm{CP}), \mu_{\mathrm{c}}$ is the pure fluid dynamic viscosity in a twophase fluid $(\mathrm{CP}), \alpha_{\mathrm{p}}$ is the proportion of solid particles in a two-phase fluid and $\alpha_{\mathrm{pm}}(=0.62)$ is the maximum piling concentration (maximum spherical particle concentration) of solid particles.

\section{Viscosity investigations of two-phase drilling compound using commercial viscosimeter}

A commercial viscosimeter has been used for direct measurement of the dynamic viscosity of the binary drilling fluid and for the two-phase drilling compound. The viscosimeter is a TVe-05 (Fig. 1) from the Jean Lamy company.

The viscosity of pure water and pure drilling fluid has been measured at different temperatures in order to verify the calibration of the viscosimeter. The measurement values have been compared with the theoretical values for water or with measurements already made by Talalay and Gundestrup (1999) for the binary drilling fluid. For the binary drilling fluid, the viscosimeter results have also been compared with the empirical relationship (from Dubovkin and others, 1985):

with

$$
\lg \lg (\nu+1)=\frac{C}{T_{k}}-D
$$

$$
(\mu=\rho \nu),
$$

where $T_{\mathrm{K}}(\mathrm{K})$ is the temperature, $\nu$ (cSt) is the kinematic viscosity and $\mu$ is the dynamic viscosity $(\mathrm{CP})$. Coefficients $C$ and $D$ have been determined for the binary drilling fluid 


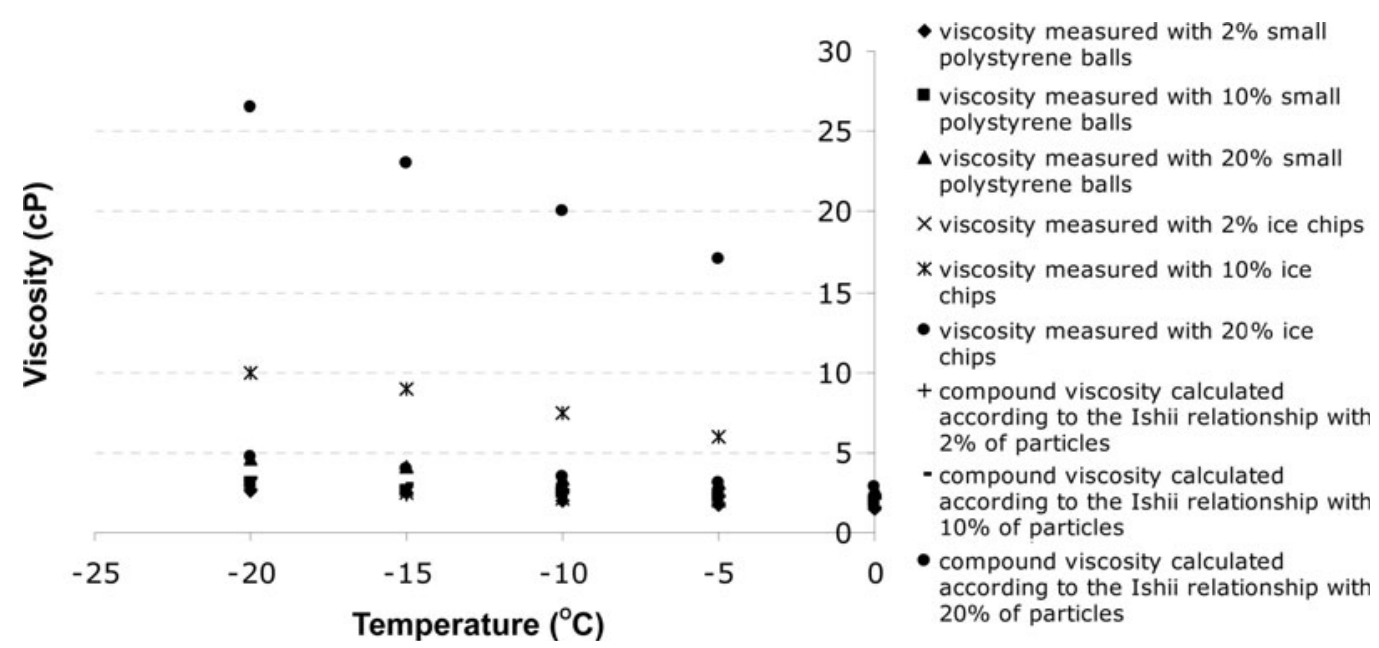

Fig. 4. Viscosity of binary drilling fluid (D60 and HCFC-141b) with different types of solid particles in suspension.

(D60 and HCFC-141b) (Gundestrup and others, 1994). In this case, $C=333.4$ and $D=1.6$.

The measurements obtained with the viscosimeter were very close to the results of Talalay and Gundestrup (1999), with $<10 \%$ deviation (Fig. 2). Given this calibration, measurements on the real two-phase drilling-fluid compound (ice chips and drilling fluid: Exxsol D60 and HCFC-141b) were made using real ice chips (obtained after machining ice in a

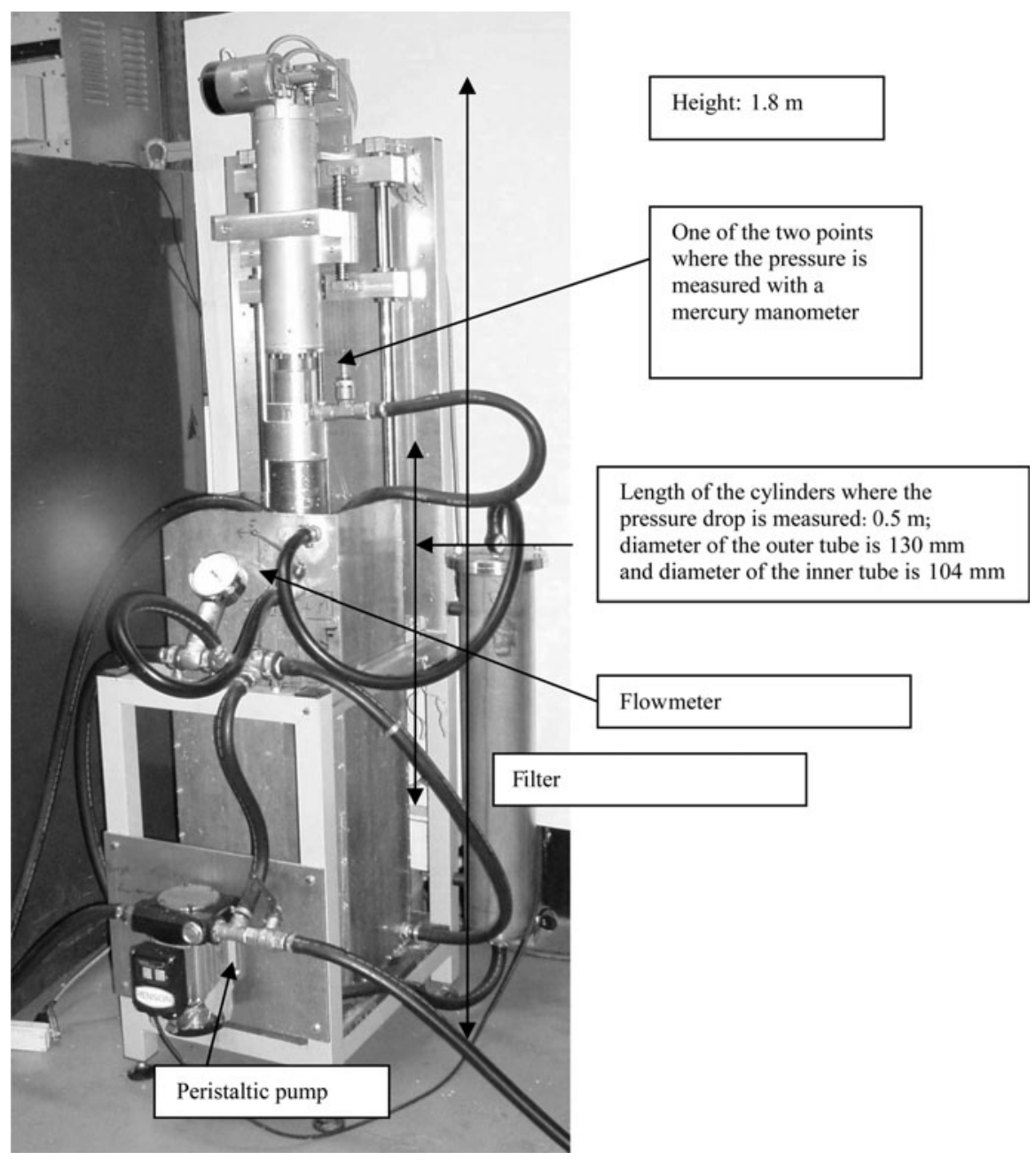

Fig. 5. Photograph of the experimental set-up. Total dimensions are length $0.8 \mathrm{~m}$, width $0.8 \mathrm{~m}$, height $1.8 \mathrm{~m}$. The fluid flow is maintained by a peristaltic pump powered by an a.c. motor. A pressure drop is measured between two points separated by $1 \mathrm{~m}$, with two mercury manometers. A peristaltic pump maintains a fluid flow rate with particles in suspension. The fluid is provided to the lower part of the cylinder through a pipe. At the bottom and at the top of the cylinder, where the pressure drop is measured, a mercury pressure gauge is plugged. The fluid returns to the pump through a filter, which retains the solid particles. 


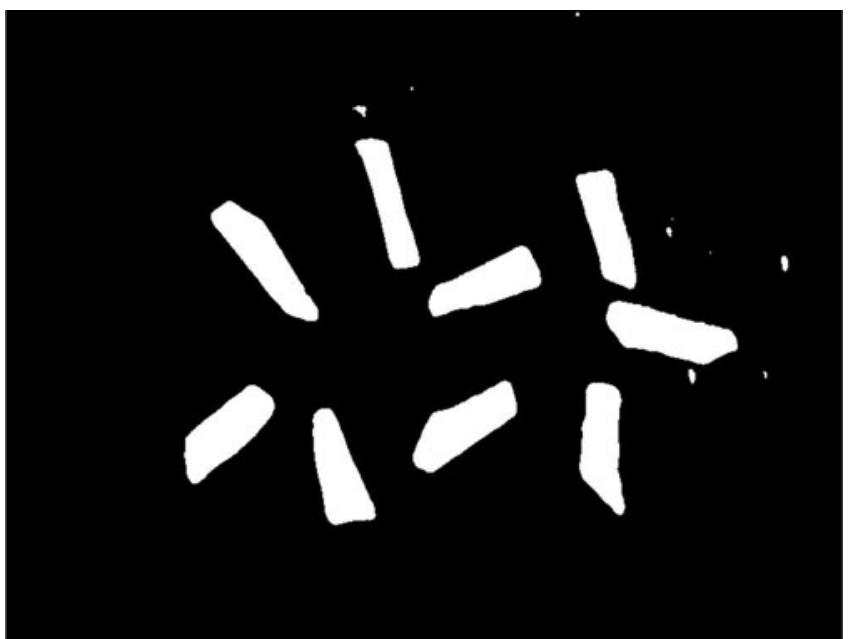

Fig. 6. Photo of small polystyrene thin strips: $L=1.5 \mathrm{~mm}, I=0.3$ $\mathrm{mm}, h=0.1 \mathrm{~mm}$.

cold room with a drill head) or small polystyrene balls $(0.7 \mathrm{~mm}$ diameter; Fig. 3). These solid particles are about the same size as real ice chips, and nearly the same density as ice $\left(920 \mathrm{~kg} \mathrm{~m}^{-3}\right)$. The measurements were performed at different temperatures and for different volumetric solid particle concentration. The results (Fig. 4) fit well with the theory for spherical particles, but not for flat particles such as ice chips. It seems that viscosity of this two-phase fluid is linked to the particle geometry.

\section{Viscosity investigations of two-phase drilling compound using an experimental set-up}

Viscosity measurements were made using an experimental set-up (Fig. 5) with water with temperature in the range 10$15^{\circ} \mathrm{C}$ instead of the binary drilling fluid in the range 0 to $-20^{\circ} \mathrm{C}$. At this temperature, water viscosity is in the same range as the binary drilling-fluid dynamic viscosity, i.e. 1.21.3 cP. Small polystyrene balls or thin plastic strips (Fig. 6) were used instead of real ice chips. This experimental method is more accurate than the commercial viscosimeter for high ice concentration (for high solid particle concentration). The choice of water at $10-15^{\circ} \mathrm{C}$ was made to simplify
Table 1. Parameters for the calculation of the correction factor

\begin{tabular}{lccc}
\hline & \multicolumn{2}{c}{$\alpha_{\mathrm{p}}<15 \%$} & $\alpha_{\mathrm{p}}>15 \%$ \\
& $A$ & $B$ & $C=$ const. \\
& & & \\
\hline $100 \%$ balls & 2.8437 & 1.1315 & 1.57 \\
$75 \%$ balls and 25\% strips & 8.8811 & 1.224 & 2.51 \\
$50 \%$ balls and 50\% strips & 15.882 & 1.2033 & 3.8 \\
$25 \%$ balls and 75\% strips & 19.956 & 1.4179 & 4.75 \\
$100 \%$ strips & 27.922 & 1.4815 & 6.1 \\
\hline
\end{tabular}

the experimental procedure so that a greater number of tests could be performed. Although the density of the polystyrene strips does not ideally match the water density, we never observed settling of the strips, and conclude that the $10 \%$ density mismatch does not disturb our measurements. These experimental measurements (at constant temperature, with different ice concentration or particle shapes) were performed in order to establish a general link between viscosity and particle geometry, which could be extended to many situations, not just ice-drilling fluids.

The method is based on the Couette principle, which allows calculation of the apparent viscosity of a fluid mixture from the measured pressure drop in the flow within a gap between two coaxial cylinders considered infinitely long. The viscosity can be expressed (Mityar, 2006) with parameters which can be measured with this set-up:

$$
\mu=-\frac{\pi \Delta p}{8 / Q}\left[\left(r_{2}^{4}-r_{1}^{4}\right)+\frac{\left(r_{2}^{2}-r_{1}^{2}\right)^{2}}{\ln \left(\frac{r_{1}}{r_{2}}\right)}\right]
$$

where $Q$ is the flow rate $\left(\mathrm{m}^{3} \mathrm{~s}^{-1}\right), l$ is the length (here $0.5 \mathrm{~m}$ ) of the two tubes where the pressure drop, $\Delta p$, is measured, and $r_{1}$ (here $0.113 \mathrm{~m}$ ) and $r_{2}$ (here $0.103 \mathrm{~m}$ ) denote the diameter of the two cylinders.

Experiments have been carried out for different volumetric fractions of polystyrene balls and thin plastic strips, starting from $100 \%$ plastic balls (and no thin strips) up to $100 \%$ thin plastic strips (Fig. 7).

These results also show a high dependency of viscosity on particle geometry. It seems that there is a linear behaviour of

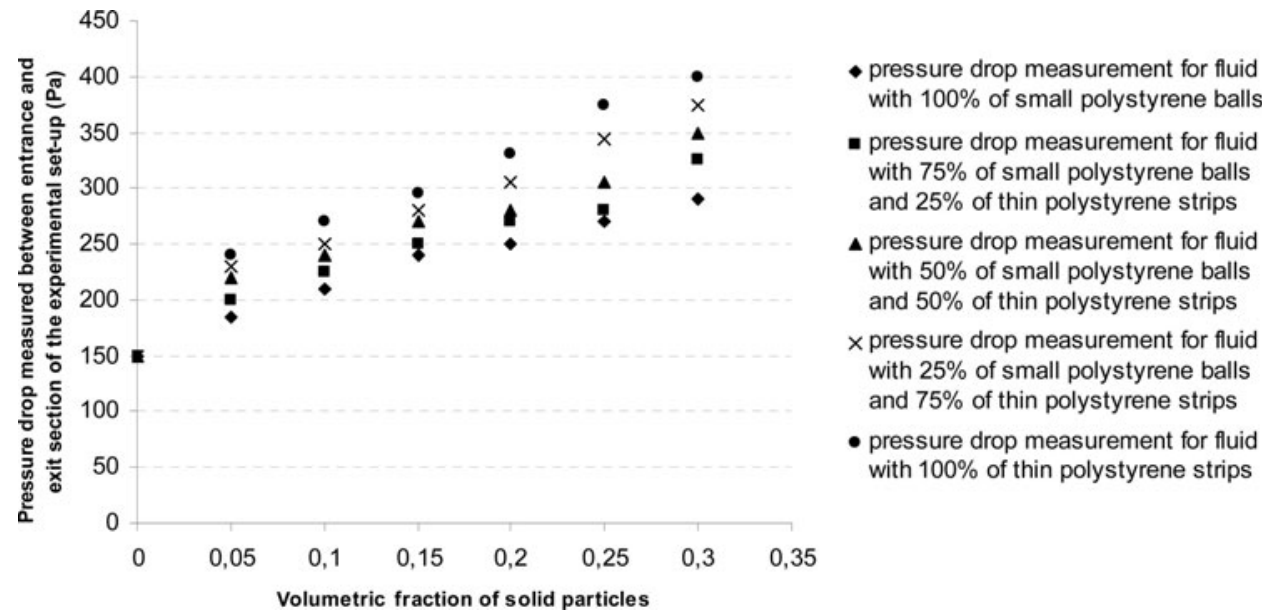

Fig. 7. Pressure drop measured between the entrance section and the exit section of the experimental set-up versus volumetric fraction of solid particles. 


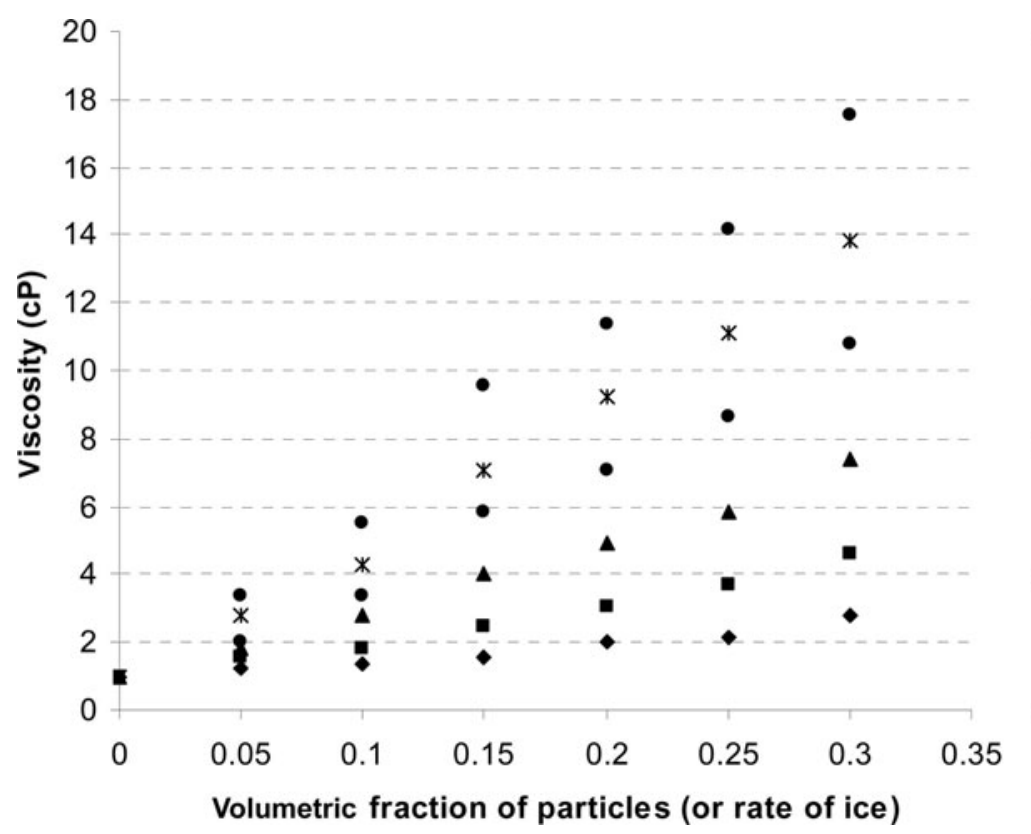

viscosity calculated using the Ishii relationship for different volumetric fractions of solid particles

viscosity (deduced from pressure drop measurement) for fluid $w$ ith $75 \%$ of small polystyrene

$\Delta$ viscosity (deduced from pressure drop measurement) for fluid with $75 \%$ of small polystyrene balls and $25 \%$ of thin polystyrene strips

- viscosity (deduced from pressure drop measurement) for fluid $w$ ith $50 \%$ of small polystyrene balls and $50 \%$ of thin polystyrene strips

* viscosity (deduced from pressure drop measurement) for fluid $w$ ith $25 \%$ of small polystyrene balls and $75 \%$ of thin polystyrene strips

- viscosity (deduced from pressure drop measurement) for fluid $w$ ith $75 \%$ of small polystyrene

Fig. 8. Viscosity deduced from the pressure-drop measurements versus volumetric fraction of solid particles for different types of solid particle.

the viscosity with volumetric fraction of particles (Fig. 8). Thus, a correction factor has been introduced in order to find a relationship that takes into account both the particles' geometry and concentration (Fig. 9):

$$
C=\frac{\mu_{\text {exp }}}{\mu_{\text {Ishii }}}
$$

where $\mu_{\text {exp }}$ is the experimental viscosity (cP) and $\mu_{\text {Ishii }}$ is the value of the viscosity obtained by calculation with the Ishii relationship (cP). The results suggest that the form of the correction factor $C$ could be expressed as:

$$
C=A \alpha_{\mathrm{p}}+B,
$$

with different values for $A$ and $B$ (Table 1 ), which depend upon the volumetric fraction of balls and thin strips.

This relationship has been used to calculate the viscosity of the two-phase fluid (D60/HCFC-141b and solid particles) for different concentrations of small particles or for ice chips (considered as thin strips). The results have been compared with the measurements made during this study both for spherical particles and for ice chips (Fig. 10). The uncertainty between the empirical relationship (taking into account the correction factor) and the experimental results is lower than $5 \%$. Consequently, the mean viscosity of a drilling compound (drilling fluid and ice chips) can be expressed as:

$$
\mu_{\mathrm{m}}=C \mu_{\mathrm{c}}\left(1-\frac{\alpha_{\mathrm{p}}}{\alpha_{\mathrm{pm}}}\right)^{-2.5 \alpha_{\mathrm{pm}}} .
$$

\section{CONCLUSION}

The goal of this study was the characterization, to first-order precision, of the main physical properties (i.e. viscosity and density) of a two-phase fluid at different temperatures and for various concentrations of solid particles. From our knowledge of these two parameters, it is possible to perform calculations and pursue numerical modelling of the behaviour

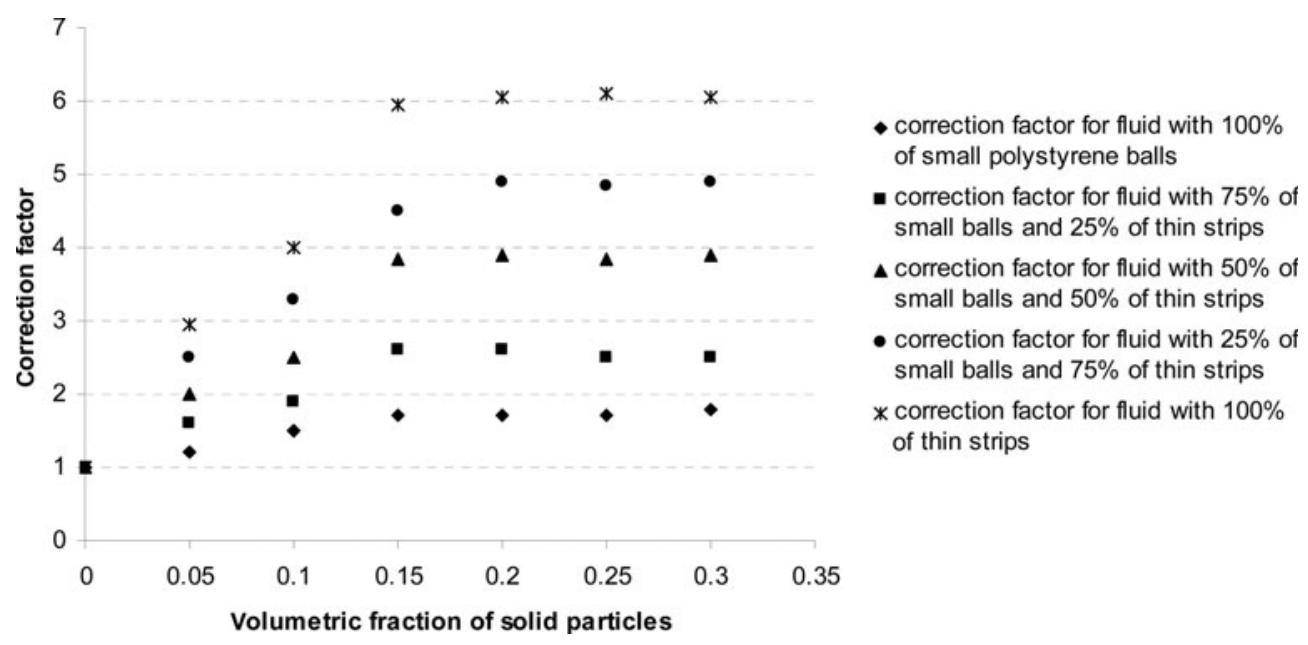

Fig. 9. Correction factor (obtained by dividing the viscosity of a fluid with solid particles in suspension by the viscosity of the same fluid that should be obtained while using the Ishii empirical relationship) versus volumetric fraction of solid particles (spherical or thin strips). 


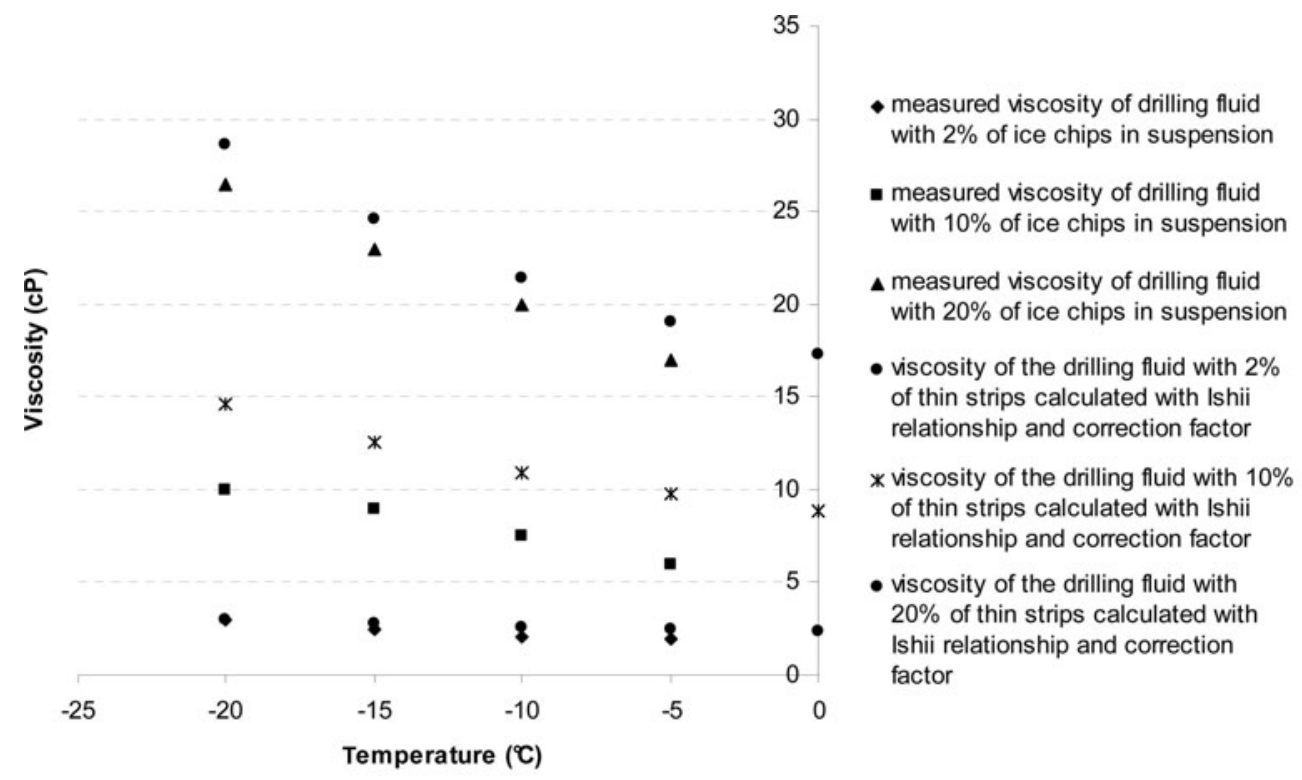

Fig. 10. Comparison between measured viscosity of drilling fluid with ice chips in suspension and calculated viscosity using the Ishii relationship with the correction coefficient for drilling fluid with thin strips in suspension.

of the two-phase flow around an ice-core drilling head (mainly with simple modelling software integrated with drawing software like Flow Works). It has been established that the mean drilling-fluid viscosity (together with ice chips) will increase with particle size or with particle concentration, and that this viscosity is highly linked with the solid particle geometry.

\section{REFERENCES}

Augustin, L. and A. Antonelli. 2002. The EPICA deep drilling program. Mem. Natl. Inst. Polar Res., 56, Special Issue, 226-244.

Dahl-Jensen, D. and 8 others. 2002. The NorthGRIP deep drilling programme. Ann. Glaciol., 35, 1-4.

Dubovkin, N.F., V.G. Malanicheva, V.G. Massur, P. Yu and E.P. Fedorov. 1985. Physical-chemical and operating characteristics of jet fuels. Moscow, Himiya. [In Russian.]

Gundestrup, N.S., H.B. Clausen, S.B. Hansen, and S.J. Johnsen. 1994. Hole liquids and gaskets for the Istuk deep ice core drill. Mem. Natl. Inst. Polar Res., 49, Special Issue, 327-334.
Ishii, M. and K. Mishima. 1984. Two-fluid model and hydrodynamic constitutive relations. Nucl. Eng. Des., 82(2-3), 107-126.

Mityar, H. 2006. Approche théorique et expérimentales des écoulements diphasiques dans les têtes de carottier pour le forage glaciaire. (PhD thesis, Institut National Polytechnique de Grenoble.)

Mulvaney, R., O. Alemany and P. Possenti. 2008. The Berkner Island (Antarctica) ice-core drilling project. Ann. Glaciol., 47, 115-124.

Sala, M. and 10 others. 2008. Evidence of calcium carbonates in coastal (Talos Dome and Ross Sea area) East Antarctica snow and firn: environmental and climatic implications. Earth Planet. Sci. Lett., 271(1-4), 43-52.

Talalay, P.G. and N.S. Gundestrup. 1999. Hole fluids for deep ice core drilling: a review. Copenhagen, University of Copenhagen.

Talalay, P.G. and N.S. Gundestrup. 2002a. Hole fluids for deep ice core drilling. Mem. Natl. Inst. Polar Res., 56, Special Issue, 148-170.

Talalay, P.G. and N.S. Gundestrup. 2002b. Hydrostatic pressure and fluid density profile in deep ice bore-holes. Mem. Natl. Inst. Polar Res., 56, Special Issue, 171-180. 